\title{
LOCALIŹAÇÕES ESPECIAIS DOS PROCESSOS SUPURATIVOS NA PELE E NO TECIDO LINFATICO (*)
}

\author{
ARY SIQUEIRA \\ 1.० assistente
}

Proseguindo no estudo das molestias infecciosas em geral, estudaremos na aula de hoje, os processos supurativos da pele.

\section{a) FURUNCULO}

E uma inflamação supurativa do aparelho pilo-sebaceo e do derma que o rodeia, produzida pela colonização no foliculo piloso do estafilococo e terminando pela necrose e eliminação em massa dos tecidos afetados.

Etiologia: - Os germens que aparecem como fatores determinantes da imensa maioria dos furunculos, são os estafilococos, produtores nos meios de cultura, de um pigmento amarelo. Si bem que nos deparamos por vezes com estafilococos não produtores de pigmentos, parece que, na realidade, trata-se somente de variedades adaptivas de um mesmo germen. $O$ estafilococo está, como sabemos, abundantemente espalhado pela natureza e é muito provavel que a especie implicada num determinado processo varie segundo o meio em que habite. Esse germem não é capaz de atravessar o revestimento cutaneo, mas é capaz de vencer a barreira muito mais fragil que the opõe o epitelio das glandulas sebaceas que afloram no ostio do foliculo piloso. Nestas condições, é suficiente um atrito para que esses germens que vivem saprofiticamente sobre a pele, passem para dentro dos foliculos. Por isso os furunculos se apresentam, sobretudo nas zonas da pele mais expostas a atritos, como é a nuca ou a maceração do suor, como é o caso das dobras cutaneas. Os pequenos traumatisinos como picadas infectadas e picadas de insectos, podem produzir furunculos em qualquer ponto da superfi-

(*) Aula taquigrafada pelos alunos. 
cie da pele, porem, mais frequentemente surgem nas zonas em que a pele é relativamente fina e mais rica em glandulas sebaceas e sudoriparas, como é o caso da axila das regiões pudendas, nariz e a nuca. E' interessante o fato que a preferencia 'dos furunculos pela nuca é, por assim dizer, um privilegio exclusivo do homem. A raridade dos furunculos na nuca da mulher, não se explica suficientemente pela distribuição especial dos pelos dessa região no sexo feminino. Tem-se observado que as mulheres masculinizadas apresentam com frequencia furunculos da nuca, como um verdadeiro caracter sexual de masculinidade.

Todas as enfermidades gerais debilitantes parecem favorecer o aparecimento de furunculos. E quasi constante na convalescença de infecções graves, especialmente de febres tifoides, o aparecimento de furunculos. Com igual frequencia aparecem associados os furunculos aos transtornos do metabolismo hidrocarbonado, tanto assim que, muitas vezes, uma erupção de furunculos leva sempre a suspeita de diabetes que, muitas vezes não se diagnostica pela glicosuria, porem por uma glicemia ou por alterações na curva de eliminação dessa substancia, parecendo mesmo que a presença de assucar nos tecidos exalte a virulencia dos estafilococos.

Um furunculo quasi nunca é isolado; a regra é que venha acompanhado de numerosos outros, dando lugar áquele quadro denominado furunculose. Sabemos que a infecção pelo estafilococo não dá imunidade, mas sim, predispõe, ou melhor, o que acontece é que aquelas zonas da pele que apresentaram furunculos uma vez, permanecem em estado de microbismo latente. Seja como for, a furunculose sugere sempre a existencia de transtornos nutritivos, muitas vezes passageiros, mas que devem ser investigados cuidadosamente.

Anatomia patologica: A foliculite se desenvolve preferencialmente no tecido conjuntivo das glandulas, o qual se continua sem limite de separação com o derma e tecido celular sub-cutaneo. Este tecido se condensa em torno do foliculo e por debaixo dele, formando como que colunas, chamadas colunas adiposas de Collins-Warrews; cuja base localiza-se em pleno tecido hipodermico. Conforme a profundidade que alcança a infecção ao longo dessas colunas, produzirse-á uma foliculite simples, uma dermite ou um verdadeiro flégmão superficial.

Em qualquer um desses casos, as toxinas proteoliticas estafilococicas produzem : uma necrose circunscríta desse tecido, convertendo-o numa massa amarelada, de aspeto manteigoso. A reação inflamatoria que se processa em torno desse tecido necrosado, dá lugar a delimitação dessa massa necrotica, com sua eliminação para o exterior, por uma solução de continuidade da pele. Dizemos então que o furunculo eliminou o carnegão.

Sintomatologia: A sintomatologia oriunda de uma furunculose é bem conhecida de todos, dispensando a sua detalhada descrição. O desenvolvimento do furunculo traduz-se por uma sensação de pi- 
cada no ponto da pele onde se desenvolve, seguida quasi que imediatamente de calor e dor intensa. A area dessa lesão apresenta todos os caracteres de uma inflamação aguda, elevando-se quasi em seguida sob a forma de uma pequena vesicula. No vertice dessa elevação surge, ao fim de 2 a 3 dias, um pontinho amarelado, que rompendo-se, dá saida a uma pequena quantidade de puz. Essa abertura alarga-se gradativamente até que, atravéz dela, se elimina o carnegão. Desse momento em deante, os fenomenos inflamatorios cedem bruscamente, subexistindo no lugar do furunculo uma cratera ulcerosa que se enche de tecido de granulação, fechando-se rapidamente, permanecendo por fim, uma pequena cicatriz.

Complicações: O furunculo é por si mesmo, uma afecção benigna e somente por multiplas recidivas é que vem a ter um signicado maior. Está provado que o furunculo é menos local do que parece, pois a maioria dos furunculos é acompanhada de infartamentos dos ganglios linfaticos regionais, o que demonstra uma extensão do processo ao longo dos linfaticos. Em certas ocasiões, estas adenites terminam por supurações. Algumas infecções supurativas mais graves, como a ostei-mielite, é muitas vezes consequencia ao aparecimento de furunculos. Neste caso serviram de porta de entrada dos germens para o sangue, que os transportou ao foco osseo.

A infecção sanguinea faz-se em alguns furunculos de uma maneira massiça, e é aqui que eles tem uma gravidade especial. É o que sucede com os furunculos da face, especialmente do labio superior, qúe se desenvolvem em um tecido de malhas densas onde se inserem os musculos da expressão e, portanto, em contato com veias muito superficiais. Daí a facilidade com que essas veias são infectadas pelo conteudo dos furunculos, e como tem comunicação direta com os seios do craneo, ha uma infecção dos mesmos, determinando acidentes mortais na maioria dos casos.

Tratamento: - Tratar um furunculo é relativamente cousa sem importancia; impedir suas recidivas é que é importante. Nestas palavras se concreta a atitude que deve tomar o cirurgião perante esta pequena afecção tão espalhada entre os homens. Efetivamente, para a maioria dos furunculos, não se torna necessaria uma intervenção operatoria. A sua abertura com o bisturi ou com o termo-cauterio, só é justificada quando parecem profundos, por que nestes casos tardam muito para abrir-se expontaneamente. Nos casos correntes, o unico meio de que se deve lariçar mão é aquele de precipitar essa. evolução, macerando a pele por meio da aplicação de emolientes ligeiramente antisepticos. As cataplasmas embebidas em soluções aquosas de timol são o que ha de melhor, pois'diminuem sensivelmente a dor. Quando aquele ponto amarelado surge no apice da vesicula furunculose, é conveniente abri-lo com o galvano-cauterio e extrair o carnegão com uma pinça. A partir deste momento aplicam-se sobre a ulcera furunculosa substancias que permitam que se mantenha a ventilação da pele. 
Os tratamentos abortivos, como as injeções de fenol no foliculo, toque com tintura de iodo, refrigeração do foco furunculoso com neve carbonica, e irradiações de lampadas de quartzo, são. sumamente dolorosas e, na maioria das vezes não fornecem melhores resultados que a cataplasma emoliente.

Os furunculos da face não devem ser de forma alguma incomodados. O melhor tratamento é a aplicação local de cataplasmas de timol. E conveniente tambem informar o paciente do perigo que corre coçando o foco furunculoso, assim como falando ou fazendo gestos. O tratamento geral é tambem indicado nestas circunstancias, mas uma vez declarada a infecção dos seios cranianos, toda a terapeutica é inutil.

Evitar a recidiva dos furunculos é, como dissemos, a questão mais delicada da terapeutica. Indicam-se para estes casos:

$1 .^{\circ}$ - A vacinoterapia, feita com injeção subcutanea de vacinas de. stock ou autovacinas, preparadas com culturas de germens do proprio enfermo. Si bem que em alguns casos esta terapeutica surte resultados, na maioria dos casos o seu efeito é completamente nulo. As autovacinas parecem, em geral, mais eficazes, principalmente nas furunculoses, que condicionam mesmo um estado de imunidade que dura um certo tempo. O emprego da vacinoterapia como tratamento curativo de furunculos graves é inutil e bastante perigosa, pois que a chamada fase negativa da vacinação pode coincidir com a exaltação do processo furunculoso e agravar as suas manifestações.

2. :- A vcinoterapia local, feita mediante aplicações sobre a região afetada, de compressas embebidas em caldos microbianos preparados de diversos modos, dá resultados muito mais inconstantes, que o das vacinas gerais." Segundo Besredka, esses liquidos contem um antivirus produzido pelo estafilococo, que exerceria sobre ele, uma ação paralizante.

3. ${ }^{\circ}$ - O tratamento geral ou local pelo Bacteriofago de D'Herelle, fornece resultados pouco convincentes.

4..$^{\circ}$ - A autohemoterapia não fornèce tambem resultados satisfatorios.

5. - A quimioterapia por meio de substancias com ação letal sobre o estafilococo, apenas encontra aplicação na furunculose vulgar, não parecendo capaz de evitar as recidivas.

$6^{\circ}$ - A cura dos transtornos do metabolismo se impõe em algumas furunculoses e é um dos meios mais eficazes para o seu tratamento.

$7^{\circ}$ - A radioterapia tem sido empregada ultimamente na terapeutica da furunculose, particularmente, naquela da face, com resultados bastante satisfatorios. As aplicações de radio tem influido poderosamente para apressar a cura dessa afecção, por sua ação sobre os estafilococos e por aumentar as resistencias organicas: Além disso, as aplicações de radio agem beneficamente sobre a dor, não 
imediatamente, mesmo porque no inicio das aplicações ha um recrusdecimento da dor, mas posteriormente.

Finalmente para concluir este capitulo, sou de opinião de que quasi sempre a cura do processo furunculoso se processa pelo aumento da resistencia organica e, quando o organismo não reage, é completamente desnecessaria uma intervenção que somente viria agravar as já prẹcarias condições do individuo. Particularmente, nos casos de furunculos da face, este preceito deve ser seguido a risca, porque, enquanto não se delimitar a infecção, ela tende a progredir e nestes casos, a intervenção só serviria para peiorar o quadro clinico da molestia.

\section{b) ANTRAX}

O antrax é uma afecção muito semelhante ao furunculo, nada mais representando do que uma aglomeração de furunculos profundos com necrose extensa do tecido celular que os separa. $E^{\prime}$ conveniente notar que na literatura alemã, reserva-se esta denominação para a infecção determinada pelo bacillus anthracis. $O$ antrax compreendido no seu justo significado tem o mesmo agente etiologico que o furunculo, somente que revela um comprometimento mais ou menos grave do estado geral, surgindo particularmente nos diabeticos ou nos portadores de molestias renais.

Causas: As causas determinantes do antrax, são as mesmas do furunculo, sendo que aqui colaboram muito mais ativamente, os fatores gerais. Efetivamente, o antrax é uma molestia da idade madura e o seu aparecimento, revela sempre a presença de profundos transtornos constitucionais. $\mathrm{Na}$ maioria dos casos, como dissemos, trata-se de diabetes ou dos chamados estados pré-diabeticos.

Sintomas: As primeiras manifestações subjetivas do antrax, não diferem daquelas do furunculo, porém a dor é sempre muito mais intensa e o estado geral se altera, já precocemente. A região afetada, que soe ser a nuca ou a espadua, apresenta uma extensa tumefacção violacea, muito dura e infiltrada, querendo isto significar que, em toda a extensão dessa zona não podemos separar a pele dos planos profundos. Não tardam a surgir no centro dessa zona, nu- merosas vesiculas que se ulceram, deixando entrever um fundo amarelo-acinzentado, formado por um carnegão que não se limita e nem se desprende. Toda a zona infiltrada torna-se cheia de crateras ulceradas, comparadas a um vespeiro.

A infiltração se extende perifericamente, impedindo que as porções mortificadas se desprendam e se eliminem. Desde esse momento, o antrax começa a supurar abundantemente, as vesiculas ulceradas confluem entre si formando uma extensa ulcera que dá lugar a grandes perdas de substancia. A inchação diminue então, as dores tambem e o fundo da ulcera cobre-se de um tecido de granulação qué procura compensar essa perda de substancia. 
A intepsidade desse quadro local do antrax, varia muito de um caso a outro. Entre um antrax formado por 4 ou 5 furunculos reunidos, até os antraxes difusos nos quais o processo se extende enormemente, acarretando uma verdadeira gangrena de extensas zonas: da pele, ha todas as transições possiveis.

O estado geral tamben varia muito; nos individuos não portadores de taras organicas, a fébre é muito alta, sem acontecer nada. de grave. Os diabeticos, inversamente, soem apresentar! crises de acidose, gravissimas, com toda a sintomatologia decorrente da mudança do $\mathrm{pH}$ sanguineo: sonolencia, delirio; dispneia, anuria, etc. A morte sobrevem com maior frequencia, mais por causa do coma do. que mesmo pela intensidade dos fenomenos locais.

Diagnostico: Via de regra se impõe o diagnostico, pois é possivèl a confusão com a pustula maligna; processo que durante muito. tempo foi confundido com o antrax. A escara negra do carbunculo, rodeada de pequenas vesiculas e sua localização quasi exclusiva na. bochecha, são sinais patognomicos dessa afecção. Tambem é facil confundir o antrax com os flegmões difusos subcutaneos, sendo que ha nestes, uma particicipação tardia da pele, que nunca vem apresentar a infiltração caracteristica do antrax. Praticamente, o quie deve sèr levado em consideração no antrax, é a apreciação do estado. geral do individuo.

Tratamento: a) A abertura ampla do foco até desbordar extensamente os limites da infiltração, é o tratamento mais aceito atualmente. Geralmente se pratica uma incisão crucial que atinge os planos aponevroticos, extirpando-se os tecidos esfacelados ou então, cauterizando-os com o termocauterio ou com o bisturi eletrico, tamponando-se em seguida a brecha. No caso, do processo continuar a progredir, deve-se ampliar a incisão. Riedel aconselha que se faça. o mais precocemente posssivel, uma extirpação total do foco, a semelhança dum tumor maligno, sem nos preocuparmos com o tamariho da brecha resultante.

b) Muitos autores, entretanto, acham preferivel o tratamentở conservador, considerando que o traumatismo operatorio, agrava a situação local e constitue a porta de entrada para uma infecção generalizada. Alguns deles contentam-se com a vacinoterapia ou com a bacteriofagoterapia, associadas ou não á autohemoterapia; outrosempregam o tratamento hiperemizante de Bier, aplicando ventosas sobre o foco; outros ainda valem-se da ionização com o ion zinco e, alguns, recomendam a Roentgenterapia.

\section{c) ERISIPELA}

E' uma dermite produzida por uma raça especial de estreptococcos hemoliticos que foram descritos pela primeira vez por Fehleisen, que acreditava tratar-se de um germem especial. 
Etiologia: A natureza estreptococicca da erisipela não é atualmente posta em duvida. Tanto é verdade isto, que no decurso de uma supuração cronica, tipicamente estreptococcica, (feridas infectadas, fistulas comunicantes com focos profundos de infecção), apresenta-se bruscamente uma verdadeira difusão da infecção á pele vizinha, em maior ou menor extensão. Dizemos então, que a ferida se erisipelou, e não resta"duvida que a dermite é uma afecção secundaria a infecção primitiva piogena.

Em certas ocasiões tambem se produz a erisipela por uma contaminação direta com um material infectado. Este fato era tão frequente antigamente, que de vez em quando, se observavam nos serviços hospitalares, verdadeiras epidemias de erisipela, tanto assim que se considerava essa molestia como uma infecção geral de natureza miasmatica. Semmelweiss dedicou toda a sua vida á convencer os medícos de sua epoca, que esse miasma era levado por suas proprias mãos. Não se podia crer então, que a erisipela das feridas, assim como as infecções puerperais, eram quasi sempre o resultado de um contaǵio direto entre um enfermo e outro. A asepsia fez desaparecer essas erisipelas em serie, das salas hospitalares.

Outrora, era-se propenso a acreditar que a erisipela nada mais era do que uma localização particular do estreptococo, não sendo considerada em absoluto como uma infeç̧ão especial. Efetivamente, nenhưma diferença existe, á primeira vista, entre os estréptococcos procedentes de um fóco de erisipela e aqueles que são isolados dos flegmões, das flebitis e outras supurações.

Não obstante, nestes ultimos annos, voltou-se á idea da especificidade do germen da erisipela. Os autores que creem nisto, fundamentam este seu modo de pensar, não em caracteres morfologicos nem em seu comportamento nos meios de cultura, mas na especificidade antigenica do Streptococcus erisipelatis. Efetivamente, o germem, á que se dá esse nome, revela sua personalidade, dando lugar a anticorpos especificos que o distinguem perfeitamente dos demais estreptococos não procedentes de focos de erisipela.

Esses trabalhos demonstraram, em troca, a relação existente entre a erisipela e a escarlatina. Dick conseguiu isolar de algumas raças de Streptococcus hemolitucus, uma toxina que injetada no homem produz uma erupção escarlátinosa tipica. $O$ mesmo resultado se obtem quando, a toxina procede do Streptococcus erysipclatis, bem caracterizado. Entretanto, enquanto que a reação produzida pelos Streptococcus procedente da escarlatina confere uma imunidade de longa duração, a toxina do Streptococcus erysipelatis somente confere uma inunidade passageira.

Assim se explica porque a escarlatina surge somente uma vez na vida do individuo, enquanto que a erisipela não confere em absoluto, imunidade; mas ao contrario, um $1 .^{\circ}$ surto é seguido de numerosas recidivas. Este fato é frequente não somente nas dermites erisipelatosas que partem de uma ferida infectante, como tambem nas 
erisipelas que se apresentam expontaneamente. Admite-se que nesse segundo caso, a porta de entrada do Streptococcus tenha sido uma erosão insignificante, uma placa de eczema ou uma pustula de acré.

O aparecimento de recidivas em todos estes casos obedece aparentemente as mais extranhas influencias. Nas mulheres soem coincidir com os periodos menstruais, descrevendo-se mesmo uma erisipela catamenial benigna. Outras vezes é a açã̀o do frio; outras ainda a influencia de certos alimentos, etc. Este conjunto de fatos sugere a ideia que na produção dessa infecção, desempenham importante papel, os processos alergicos. Devemos supor, que a zona da pele afectada encontra-se num estado especial de resistencia que pode desaparecer periodicamente, ou pela influencia de fatores internos; para dar lugar a um novo conflito local com as toxinas bacterianas. "Segue-se um novo periodo de resistencia e, assim sucessivamente.

Um fato clinico deve ser acrescentado a esse respeito: é a influencia benefica que as crises erisipelatosas exercem sobre o decurso das infecções cronicas.

Sintomas: As erisipelas que interessam especialmente os cirurgiões são as que se produzem como complicação das feridas operatorias ou acidentais e aquelas de antigas supurações comunicantes com a pele. Em tais casos, a erisipela inicia-se regularmente por calafrios violentos, aos quais seğue-se uma forte elevação da temperatura, acompanhada quasi sempre de cefaleia, raquialgia, vomitos, prostração e todas as sensações subjetivas de uma grave enfermidade geral. O pulso é particularmente acelerado. Quando o paciente apresenta-se conciente, não deixa de notar a sensação de ardor e repuxamento; apresentam-se os portadores da erisipela, com - o estado geral bastante afectado para que essas sensaçôes se exteriorizem. Efetivamente, somente ao fim de 24 a 48 horas, surge em torno da ferida a manifestação caracteristica da infecção: a placa erisipelatosa. Esta se apresenta como uma mancha de bordas irregulares, de cor vermelho viva na periferia e mais palida no centro. A pele, é brilhante e tensa em toda a extensão dessa mancha, parecendo un pouco elevada sobre o tecido circunvizinho, percebendo-se por vezes, pelo tacto, a linha de demarcação entre a zona inflamada e a sã.

A placa erisipelatosa extende-se rapidamente, o que não está de acordo com a gravidade da infecção. No rosto, a propagação é simetrica para ambos os lados, em forma de mariposa. Muitas vezes . a progressão se efetua por ilhotas isoladas, separadas por intervalo de pele sã, dando lugar á erisipela serpinginosa. Não raro a superficie da placa apresenta pequenas flictenas, dando a erisipela flictenular, ou extravazações sanguineas, caracterizando a erisipela ecmozica. Nos individuos idosos e nos diabeticos apresentam-se formas de erisipelas gangrenosas, muito graves, durante as quais se esfacelam grandes zonas de pele.

Nos casos correntes, a progressão da placa detem-se em 4 a 6 dias. Os fenomenos gerais cessam então, tão bruscamente como sur- 
giram e o paciente volta á normalidade.

A placa empalidece e recobre-se de uma descamação purpuracea.

Prognostico: A erisipela ataca preferencialmente as crianças e os velhos. A erisipela é particularmente grave quando assesta no umbigo dos recem-nascidos. A mesma cousa se observa na erisipela dos individucs idosos, diabeticos, renais, etc. Nos jovens sem taras a erisipela é sempre benigna.

Tratamento: Nas erisipelas simples associadas a feridas supurativas, é evidente que se deve seguir um tratamento conservador. O repouso no leito, a dieta aquosa e a aplicação de compressas humidas ligeiramente antisepticas é tudo o que se tem a fazer. Os compostos coloidais de prata, como o Protargol e o Colargol, são os mais indicados porque, são antisepticos não causticos e parecem ter uma certa ação eletiva sobre os Streptococcus. Tambem é muito usada a pomada de Ictiol. No que diz respeito ás pulverizações de sublimado é outros antisepticos fortes, empregados outrora, pincelações de colodio em torno da placa com o fito de deter sua progressão, e as injeções de antisepticos com 'o mesmo objetivo, devem ser evitadas.

O tratamento geral, deve dirigir-se sobretudo para as taras de que é portador o paciente. Afora estes casos é conveniente recomendar nos casos graves, o emprego da soroterapia. Até ha bem pouco tempo, os soros empregados eram polivalentes, mas com o emprego de soros monovalentes, tem-se obtido, melhores resultados. A imunização ativa, mediante vacinas com o objetivo de evitar as recidivas, tem fracassado sempre.

Internamente a sulfanilamida domina hoje pela sua especificidade contra o estreptococo.

O tratamento local pode tambem ser feito com o emprego da sulfanilamida e com soro antierisipelatoso de resultados pouco convincentes.

\section{HIDROSADENITES}

A hidrosadenite é um processo inflamatorio que atinge as glandulas sudoriparas, principalmente aquelas da axila. Este comprometimento das glandulas se traduz pela formação de verdadeiros abcessos nessa região. Este processo diferencia-se do furunculo porque não ha aqui processos de necrose.

$\mathrm{Na}$ maioria dos casos trata-se de uma afecção muito rebelde ao tratamento, sendo na maioria das vezes, a consequencia da falta de higiene pessoal.

O tratamento da hidrosadenite deve consistir na abertura e drenagem das glandulas sudoriparas comprometidas, intervenção essa que deve ser realizada o mais precocemente possivel. Este processo tem grande tendencia a recidivas, daí de bom alvitre o tratamento geral 
dessa estafilodermia, ser feito por autovacinas, que tem dado bons resultados.

\section{INFEÇÕES PIOGENAS DO SISTEMA LINFATICO (Linfangites e linfoadenites)}

Generalidades: A participação nas infecções piogenas dos vasos e ganglios linfáticos, correspondentes ás regiões infectadas, é muito frequente. Comprehende-se que assim deva ser, si tivermos em mente que os linfaticos constituem o sistema de drenagem dos espaços do tecido conjuntivo onde circula a linfa tissular. Supõe-se atualmente que os linfocitos estejam encarregados especialmente da ação quimica, quer dizer, da destruição das proteinas extranhas, e os elementos do reticulo-endotelio, da limpeza mecanica, isto é, da fagocitose.

Toda infecção local repercute pois, necessariamente, sobre esses orgãos linfoides, pelo menos estimulando-os á proliferação. Clinicamente traduz-se essa repercussão pelo infartamento ganglionar quer dizer, pela tumefacção dos ganglios linfaticos regionais que aparecem em quasi todas as inflamações e desaparecem quando estas cedem. Porem, si a linfa recolhida do foco, é muito infectante, produz-se nos ganglios uma inflamação, linfoadenite, que evolue por conta propria e pode terminar por uma supuração. O reprezamento da linfa nos vasos, pode determinar por sua vez, a linfangite troncular ou inflamação de suas paredes e do tecido conjuntivo que os rodeia.

De qualquer modo, a infecção tem, muito maior tendencia a atacar os ganglios que são uma escala natural da mesma, do que os vasos linfaticos, orgãos de passagem. Por isso, a adenite existe muitas vezes sem linfangite visivel. Contrariamente, não se concebe uma linfangite sem adenite dos ganglios correspondentes.

\section{LINFANGITE}

Etiologias As unicas inflamações agudas dos vasos linfaticos que tem personalidade clinica. são aquelas que se apresentam como consequencia de infecções diretas. Trata-se geralmente, de feridas infectadas dos 'tegumentos ou de infecções inflamatorias agudas da pele: o furunculo, por exemplo. Mas raramente, a linfangite tem ponto' de partida num foco de supuração articular ou osseo. E excepcional, finalmente, que a linfangite se produza por via hematogenica.

Sintomas: "Distinguem=se classicamente, duas variedades de linfangites: ticos ;

$10^{\circ}$ - A linfangite reticular ou das redes de origem dos linfa- 


\section{$22^{\circ}$ - A linfangite troncular ou dos troncos linfaticos.}

Esta distinção é puramente artificial, porque a inflamação das redes linfaticas não se exterioriza por nenhum sintoma que a distingue das inflamações do derma e do tecido celular sub-cutaneo. Somente quando aparecem inflamados os troncos linfaticos, podemos dizer que tais inflamações complicaram-se com uma linfangite.

As linfangites que se tomam como tipos para a descrição são aquelas dos membros, consecutivas ás infecções dos dedos. A pele circunvizinha do ponto infectado apresenta-se arroxeada, tumefeita e dolorosa. A mancha branca produzida pela pressão do dedo, desaparece rapidamente. Os limites destas zonas de inflamação superficial, são mal demarcados e o arroxeamento atenua-se para a periferia. Em um dado momento, surgem na porção terminal desse halo inflamatorio, numerosas linhas roxas, muito delgadas, sinuosas, mais ou menos paralelas, que se destacam sobre uma faixa de pele rosada. Gradativamente, vemos essas linhas avançar em direção ao ganglio correspondente, tornando-se menos numerosas e mais grossas, á medida que dele se aproximam. Deste modo, a faixa de pele rosada da periferia se converte pouco a pouco, num verdadeiro desenho de vasos linfaticos subcutaneos.

Passando suavemente o dedo, pode perceber-se um ligeiro relevo, produzido por esses vasos inflamados. Mais raramente, percebe-se um verdadeiro cordão endurado.

Evolução e terminação: dependem do decurso da infecção causal e da intensidade das lesões que se produziram nos troncos linfaticos. Quando estas não passam de uma hiperemia com exudação, as manifestações da linfangite cedem rapidamente emquanto melhora a situação do foco originario.

$\mathrm{Si}$ as lesões são mais profundas, produz-se uma coagulação da linfa no interior dos vasos, inflamando-se o tecido celular que os rodeia. Nestes casos a linfangite subsiste e pode terminar da seguinte maneira: $10^{\circ}$ ) pela passagem ao estado cronico, quando a obstrução do tronco linfatico e a infiltração do tecido conjuntivo que o rodeia evolue para uma fibrose; permanece então como reliquat da inflamação um cordão linfatico endurado; $\dot{2}^{\circ}$ ) por supuração, que se traduz pelo aparecimento de uma serie de abcessos em fileira ao longo do tronco afetado; $3 .^{\circ}$ ) por gangrena. Esta é inteiramente excepcional.

Diagnostico: quando uma ferida rodeia-se de um halo inflamatorio, é dificil saber si se trata de uma dermite ou de uma linfangite. Praticamente este diagnostico tem pouca importancia, sendo mais importante perceber-se a tempo que a infecção local primitiva tende a ultrapassar seus limites. $\mathrm{Si}$ as medidas tomadas surtem resultado, é provavel que tudo volte ao normal, si se trata de uma linfangite. No caso de uma dermite, a enfermidade continuará a evoluir. A distinção entre a linfangite troncular e a flebite é tambem facil; nesta o cordão é muito mais grosso e duro e, a cor da pele não se altera. Diz-se de modo geral que a flebite é palpavel e a linfangite é visivel. 
Tratamento: a linfangite não exige outro tratamento sinão aquele de repouso e calor humido. $O$ melhor tratamento é feito pela aplicação de compressas.

\section{ADENITES AGUDAS, LINFADENITES}

Etiologia: a inflamação aguda dos ganglios linfaticos é, como sabemos, um processo muito geral que acompanha não somente as infecções locais, como tambem, algumas enfermidades infecciosas generalisadas. Como exemplo temos as adenites da peste bubonica e aquelas que se apresentam na febre tifoide, escarlatina etc.

As adenites que podemos chamar cirurgicas nunca têm origem por via linfatica. Na maioria dos casos a adenite é consequente a infecções localisadas no territorio que é tributario do ganglio afetado. Algumas vezes a infecção não tomạ os ganglios regionais, mas vai se instalar em ganglios mais afastados. Assim, a adenite inguinal vem muitas vezes como consequencia de infecçóes no pé sem que sejam afetados os ganglios popliteus intermediarios. Este fato, frequentemente na clinica, talvez possa explicar-se pela existencia de anastomoses que permitem a linfa, contornar o territorio dos ganglios da região.

Em todos os casos, a localisação da adenite permite adivinhar a porta de entrada da infecção. E frequente por exemplo, que uma adenite inguino-crural apareça expontaneamente. $O$ paciente nega sofrimento e, qualquer tipo de infecção no membro inferior. Porem, examinando-se o membro, é frequente encontrarmos uma lesão no calcanhar ou um arranhão na planta do pé.

Os germens capazes de produzír adenites agudas são multiplos. As adenites inguinais venereas que seguem ao cancro mole contem o estreptobacilo de Ducrey; nos ganglios mesentericos é frequente encontrarmos bacilos coli e com maior frequencia, bacilos de Koch.

Anatomia patologica: a inflamação dos ganglios se reduz num. primeiro periodo a hiperemia ativa com edema muito intenso dos mesmos. O orgão aumenta de volume, torna-se duro e tumefeito; pelo exame microscopico notamos a presença de uma proliferação dos foliculos e uma forte diapedese, fazendo com que haja mistura dos elementos linfoides com os leucocitos polimorfo-nucleares neutrofilos.

Si a infecção não passa deste ponto, os fenomenos inflamatorios regridem e tudo volta ao normal. No caso contrario, produz-se uma supuração no interior do ganglio. Esta se caracterisa pelo aparecimento de pequenos focos que fundindo-se, transformam o ganglio numa verdadeira bolsa de puz. Entretanto, antes de chegar a esta fase, pode haver a supuração do tecido celular que rodeia o ganglio, produzindo-se um adeno-flegmão ou abcesso do tecido celular periganglionar. 
As infecções menos intensas não chegam a produzir peri-adenites e se reduzem á formação de pequenos abcessos no interior do ganglio. Ás vezes este processo termina por fibrose e o orgão se converte numa massa quasi homogenea de tecido cicatricial. Este fato é frequente nas adenites lueticas.

Sintomas: o aspecto dos ganglios simplesmente infartados é por demais conhecido. A região onde os ganglios se localisam não muda de cor a não ser que exista uma linfangite ou que sobrevenhı a supuração.

Tratamento: no primeiro periodo deve reduzir-se á aplicação de hemolientes.

O tratamento geral pode ensaiar-se sem inconveniente, enquanto a adenite não apresenta os caracteres de uma supuração. Neste caso, deve-se abrir o foco o mais rapidamente possivel, sem esperar que a supuração seja patente.

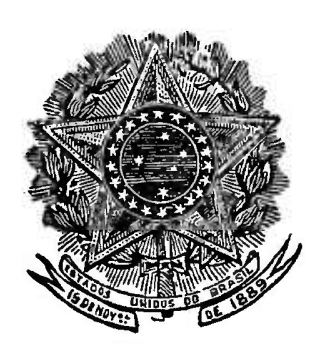

Bruno Zaratin 16. TABELIÃO DE NOTAS

Comunica aos seus amigos ter instalado o seu Cartorio á rua Marconi, 100 — telefones 4-2880 e 4-2881 - onde aguarda o prazer de sua visita, colocando ao seu dispôr os serviços que lhe estão aféctos 